\title{
Preface
}

\section{Biography of a Castle}

\begin{abstract}
Passing on to Waingate we stand on classic ground, but it is a little foreign to the tenor of our usual conversations to go so far back as to try to conjure up an imaginary picture of what the old Castle used to be. The materials for such a picture are very scanty, and all that remains to us above ground is the name (Leader 1875, 218)

The uncovering of the castle remains and part of the River Sheaf will create a new focus for Castlegate which provides a direct link with the historic roots of Sheffield (Sheffield City Council Castlegate Masterplan, EDAW 2005, 9)
\end{abstract}

The northern English city of Sheffield is not well known for its medieval heritage. Rather, the 'Steel City' gained global fame in the 18th and 19th centuries for the products of its metalworking forges, and for innovations in manufacturing processes, including those involved in the production of crucible and stainless steel (Hey 1991; 2005; 2010, 86-94). In the early 18th century, the novelist Daniel Defoe commented on the features which were to make Sheffield famous across the world, describing it as 'very populous and large, the streets narrow and the houses dark and black, occasioned by the continued smoke from the forges, which are always at work' (Defoe 1724-27, III, letter 8, part 3), while towards the end of the 19th century John Daniel Leader (1872, 371), a Sheffield newspaper proprietor and antiquarian, lamented that the city had almost lost its connection with the romance of history and is known to fame only for its hardware and smoke. In more recent times, Sheffield has become internationally recognised for its vibrant creative arts scene, through bands such as ABC, Def Leppard, The Human League, Pulp and Arctic Monkeys, but, as elsewhere, this emerged in the context of economic hardship caused, in Sheffield's case, by government cuts and the demise of the steel industry. Nowadays, the city is at least as well known to international audiences through its portrayal in the film The Full Monty (1997), an affectionate tale but one in which the ravages of post-industrial decline provide the backdrop to the story of unemployed former steel workers who became male strippers. This book sets out to present a very different account of Sheffield from the one contained within this standard narrative of industrial colossus to post-industrial rustbelt (Hey 2010, 86-94). Its focus is Sheffield Castle, one of the largest medieval castles in northern England, which was ordered to be demolished at the end of the English Civil War in the mid-17th century but has remained a powerful, if largely hidden, presence in Sheffield's urban landscape through to the present day (Figure i). This book offers an original take on an urban castle, resurrecting from the archives a building that, for over 350 years, has resided only on the horizons of the imagination but which once made Sheffield a nexus of power in medieval England.

How to cite this book chapter:

Moreland, J. and Hadley, D. (with A. Tuck and M. Rajic). 2020. Sheffield Castle: archaeology, archives, regeneration, 1927-2018, pp. xiii-xxi. York: White Rose University Press. DOI: https://doi.org/10.22599/SheffieldCastle.n. CC BY-NC 4.0, https://creativecommons.org/licenses/by-nc/4.0 


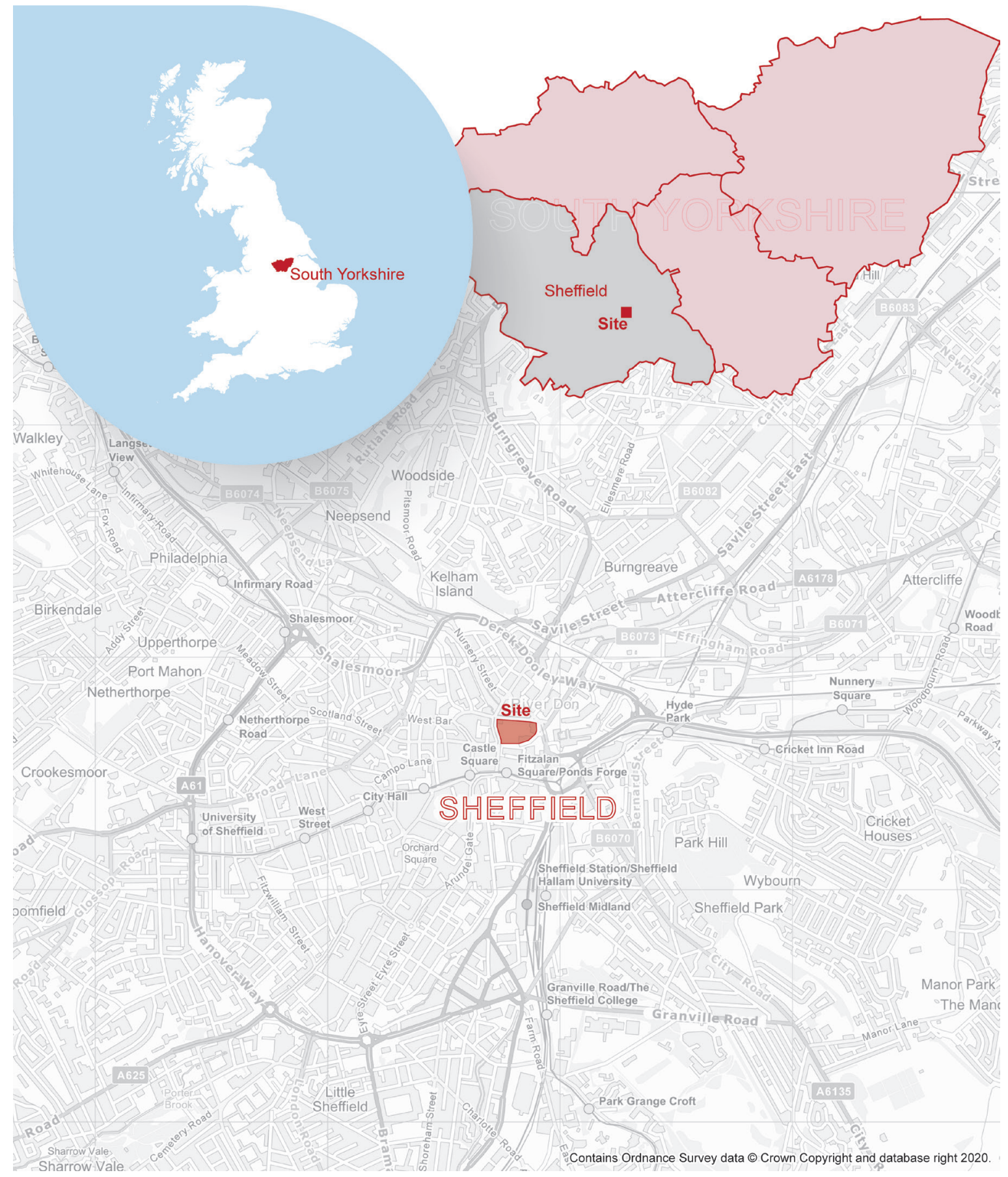

Figure i: Location maps. The location of Sheffield in Great Britain (left) and South Yorkshire (right), and the site of Sheffield Castle in the modern city centre. Wessex Archaeology.

\section{Aims of the book: the many battles for Sheffield Castle}

Since 1927, Sheffield Castle has been subject to several campaigns of archaeological recording, which have largely gone unpublished and unstudied. At the time of writing the site of the former castle stands empty and is the focus of intensive discussions about urban regeneration (EDAW 2005; Ogden 2018; University of Sheffield 2016; 2017; Figure ii). Efforts to develop the site and to attract investment into this district of Sheffield 
Wills 2016, 5-6; Darvill et al. 2019, 3-10, 289-90). Instead of relying, as had been the case since the introduction of the Ancient Monuments Protection Act in 1882, on limited legislation to protect specific monuments or (from 1979) 'archaeological areas', PPG16 sought to 'manage' the archaeological resource by embedding it within the planning system. PPG16 asserted that

archaeological remains ... are a material consideration in the planning process, and ... where it is a question of archaeological remains of national importance ... there should be a presumption in favour of their physical preservation in situ (Champion 1996, 56; also Bryant and Wills 2016, 6; Chapter 7).

One of the consequences of PPG16 within British archaeology is that an ethos of evaluation and assessment in advance of development prevails, and that the developer is responsible for paying for this.

Changes in political philosophy saw new, more community-focussed, guidance issued in 2010 called Planning Policy Statement 5: Planning and the Historic Environment. This was replaced by the National Planning Policy Framework in 2012, which simplified the guidance of PPG16 but placed the historic environment on an equal footing with economic, social and environmental considerations in planning and development decisions (Darvill et al. 2019, 288-9). There have also been attempts among archaeologists to change the management agenda from one that privileges preservation by record to an approach that enhances understanding of the past by placing 'emphasis on interpretation in addition to recording, and developing a historical narrative as the site is excavated' (Andrews et al. 2000); it is ironic that this is precisely the approach to excavation and recording that was adopted by the early and mid-20th-century excavators we shall discuss in this book. However, the well-established structures of developer funding and commercial archaeology remain (Schofield et al. 2011, 37), and such has been the success of PPG16 in creating this expectation that it is sometimes hard to remember that this is not always how it was - and we need to appreciate that difference if we are properly to understand the work of earlier generations of archaeologists, and the conclusions they drew from it.

We also have to recognise that, while PPG16 has privileged mitigation of damage to the archaeological record and an ethos of preservation by record, analysis of previous unpublished excavations falls outside of its purview. This has had profound consequences for places with long histories of unstudied archaeological investigations, especially where, as has happened for the site of Sheffield Castle, this has prevented local authorities from securing the funding required for regeneration. In 2014, a large-scale bid to the Heritage Lottery Fund was submitted by Sheffield City Council for funding to undertake 'analysis, conservation, display, interpretation and, where appropriate, reconstruction of the [castle] remains whilst revealing the larger story of Sheffield's pre-industrial evolution' as part of the regeneration strategy for Castlegate (Sheffield City Council 2014). It was unsuccessful in no small part because of 'the high risk associated with the ... unknown extent of the archaeological remains' (HLF 2014). It is clearly to be regretted that efforts to regenerate one of Sheffield's most impoverished districts have been impeded by the black cloud of an unstudied, and misunderstood, archive hanging over it. This book, therefore, not only tells the story of Sheffield Castle and its rediscovery; it also provides a crucial resource for those working to harness the city's heritage to secure urban regeneration.

\section{Structure of the book: from elite display to community regeneration}

We have structured this book to reflect the fact that it is not simply an account of a castle but rather a biography of a historic place, from its origins to its demise, and beyond into a place of myth making, memory and imagination. The book is largely framed around the excavation campaigns on the castle site, enabling us to interweave an account of the castle with those of both the excavation process of different eras and their contemporary regeneration agendas. In our aims and approach to writing this book, we set a new agenda for the study of castles as places integral to their urban communities, showing how, and why, their cultural construction continues into the 21st century. It is, in essence, an exposition of the longue durée of community engagement with a building, with important lessons for the current trend for community involvement in regeneration initiatives. Chapter 1 presents an outline history of Sheffield Castle and its elite residents, and examines its fate in the aftermath of the Civil War, based on our analysis of neglected and unpublished manuscript sources. We also reveal that more survived of the castle into the modern period than has hitherto been appreciated. The chapter introduces the various archaeological campaigns to record the remains of the castle since 1927 and summarises previous attempts to analyse and write up the unpublished records of those excavations. 
Discussions over the last 20 years about the significance of the unpublished excavations for the history and heritage of the city are also presented. Finally, we position our study within the wider context of recent archaeological research on castles.

No study of Sheffield Castle can ignore the legacy of Leslie Armstrong, better known as a prehistorian, who was living in Sheffield in the late 1920s and led the recording of the remains of the castle when they were exposed during construction work between 1927 and 1929. His paper, published in the Transactions of the Hunter Archaeological Society in 1930, has informed all subsequent accounts of the castle. As we will show in Chapter 2, however, his archive contains ample material enabling us to contextualise, and in some respects correct, this published account. Even more important is the archive of his collaborator Joseph B. Himsworth, which reveals much about the circumstances under which the remains of the castle were recorded, and presents us with a parallel narrative to that of Armstrong's published work, including information on aspects of what was seen of the castle that were not published at the time. Both were members of the local Hunter Archaeological Society, founded in 1912 and extremely influential in recording and - from 1914 through their Transactions - publishing the archaeological record of South Yorkshire and North Derbyshire. While Armstrong is the far better known figure, the archive of Himsworth takes us to the heart of historical and archaeological investigation in the inter-War years, and also reveals the considerable contributions to the recording, preservation and promotion of heritage made by local archaeological societies. Following their intervention, the remains of parts of the castle's gatehouse, courtyard buildings and other structures were preserved in brick-built chambers beneath the markets subsequently constructed on the castle site, and their work was important for placing the rediscovery of the castle in its social, cultural and intellectual context (Figure iii).

In Chapter 3, we offer a detailed analysis of what Armstrong and Himsworth saw, expanding considerably on what is known from Armstrong's published work, and examining the nature and quality of the interpretations they placed on their findings. What emerges from our study of the archives is a well-recorded insight into the castle, with an invaluable photographic record and important unpublished descriptions of what was found. However, we also reveal that caution needs to be exercised when accepting their interpretations, many of which evolved over time, owing as much to attempts to validate the contemporary written record as to the archaeological remains, and their over-enthusiastic engagement with public expectations of what the excavations would reveal. This chapter takes the form of a very detailed analysis of the archival sources, examining how Armstrong's published account came into being, what it omitted, and how the story of the castle they presented grew over the course of the investigations.

In Chapter 4 we introduce the work of Leslie Butcher, a geologist and surveyor by training, who worked in the Architect's Department of Sheffield City Council and was given the task of recording the remains of the castle uncovered during new building work from 1958 (Figure iv). While not well known outside Sheffield, he was an experienced and skilled member of the local archaeological community. He collaborated with the better-known John Bartlett, Deputy Director of Sheffield City Museum, but, aside from a brief note (Hurst 1959), none of this work was ever published. However, Butcher's extensive archive survives, comprising a hugely valuable drawn and photographic record, drafts of a paper (Butcher 1972a; 1972b; 1972c; 1972d) and the script of a lecture (Butcher 1961), which all provide crucial insights into analytical processes that differed significantly from those of Armstrong and Himsworth. His photographs and drawings provide considerable detail on what was uncovered, which, as we will see in Chapter 5, allows us to place many of the artefacts in their stratigraphic contexts. In turn, this enables us to refine and correct further some of the published claims made by Armstrong. As will become clear, the focus of Butcher's analysis was very different from that of Armstrong and Himsworth, with a greater emphasis on the topographical setting of the castle, including the manner in which it had been transformed by centuries of development on the site, and on the moat, both its form and how it was constructed to maintain water levels. In this chapter we therefore take a different approach to the archival material than that adopted for Armstrong's and Himsworth's records, as it lends itself to detailed discussion of archaeological contexts given the information available for individual excavated features (we provide that detail in an appendix to Chapter 5). This chapter also shows that recent concerns expressed that the castle remains are an impediment to regeneration of this site - because their scale and location are unknown - have been overstated, and have become part of a contemporary mythology that has emerged around the castle remains. Much of the material to assess the nature of the archaeological remains, especially relating to the moat, and to mitigate these factors in construction design, have been available all along, if largely unstudied, in the Butcher archive. As we will show, the castle remains, indeed the entire deep 


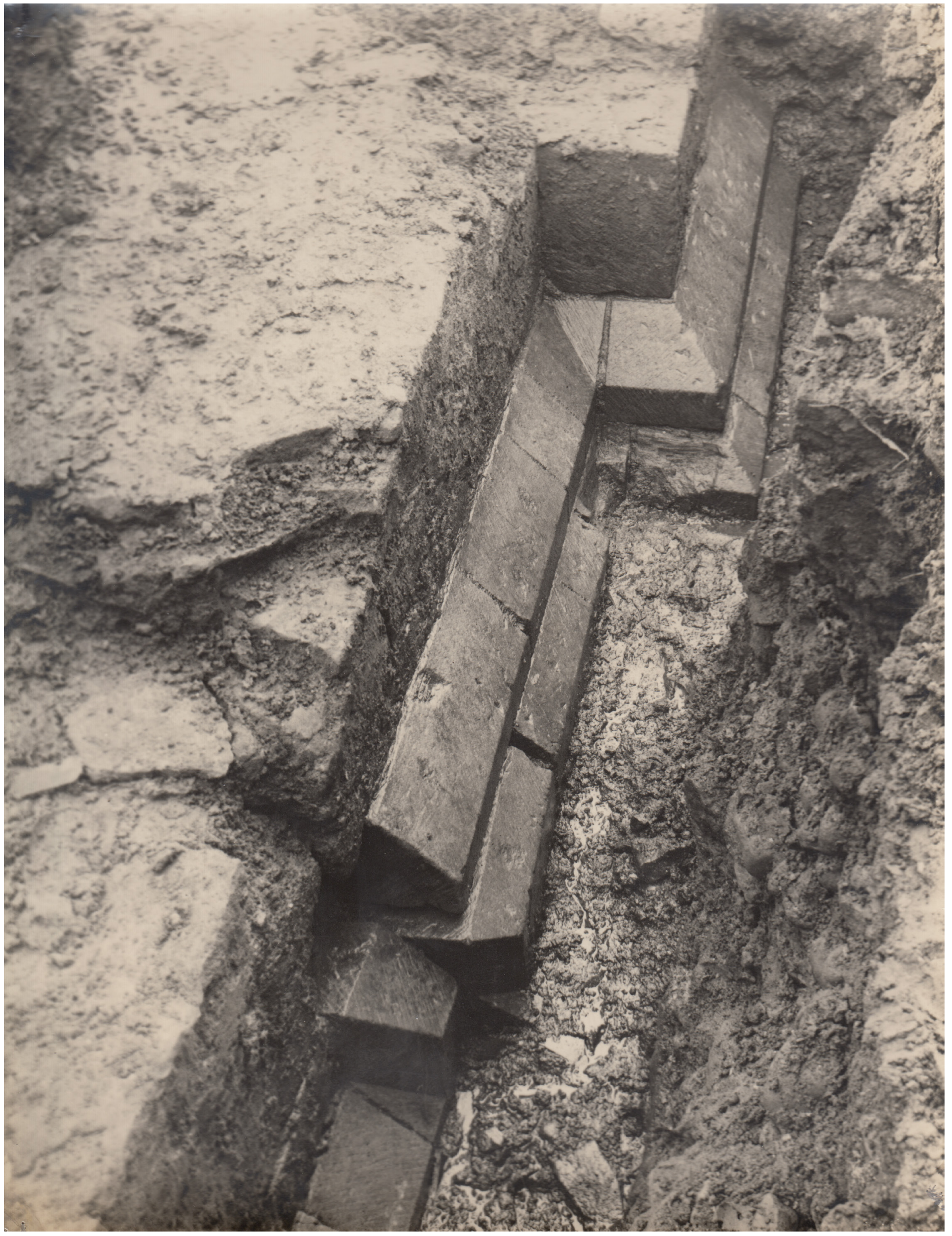

Figure iii: Part of the wall of a building in the courtyard of Sheffield Castle. Photographed by Leslie Armstrong, October 1928. Courtesy of Museums Sheffield. 
castle to guide their plans for future development. This was the first large-scale, professional excavation across the whole of the site, and our research on the early to mid-20th-century archives informed the excavation strategy both in formal meetings with Wessex Archaeology and Sheffield City Council and on a day-to-day basis during the preparations for the excavation and as it was being conducted. Uniquely in the history of archaeological exploration of Castle Hill, this was not driven by, or indeed part of, its ongoing or imminent redevelopment. Rather, it was designed to enhance our knowledge of human activity there and to clarify the scale and degree of preservation of the archaeological remains, with a view to facilitating, and informing, the future regeneration of the area. In the discussions led by the City Council over the last 20 years about what to do with the site of the former castle, the archaeological remains have often been seen as a 'problem': a disincentive to development, and an impediment to securing the funding required to regenerate this part of the city centre. However, aided by the work undertaken for this book, and by projects led by colleagues in the School of Architecture at the University of Sheffield $(2015 ; 2016 ; 2017)$, the City Council was finally able to unlock regional government 'kickstart' funding to begin exploratory work in advance of development. It is this that directly led to the excavations undertaken by Wessex Archaeology (Ogden 2018), which have provided the first modern dating evidence for the castle and important insights into subsequent developments on the site. Together we then worked in collaboration to bring all of the excavations to publication, and to advance the momentum for regeneration.

The castle did not stand in isolation, and in Chapter 8 we explore its relationship to the lordly landscape of the medieval deer park and hunting lodge to the east. A deer park had been in existence since at least the late 13th century, with a hunting lodge sitting at one of its highest points. This chapter examines the standing remains of that lodge, which date to the 15th and 16th centuries, and draws on the archives of unpublished excavations conducted between 1968 and 1980 by Sheffield City Museum (Beswick 2002; Hadley and Harlan 2011), and the reports produced following more recent excavations by ARCUS (2007-08) (McCoy 2007a; 2007b; 2009) and Hadley for the University of Sheffield (2009-11) (Mepham and Powell 2010; Burgess et al. 2011; Crewe and Askew 2012). When integrated with the documentary evidence, this reveals the scale of the impact of the castle and its wider estate on Sheffield in the medieval period and beyond. The chapter also examines the fate of the seigneurial landscape as the lodge and park began to be dismantled in the 17th century, which has had significant consequences for the landscape of the city that continue to the present day.

In Chapter 9 we examine the legacy of the castle for the people and city of Sheffield. Although demolished over 350 years ago, traces of Sheffield's castle are perpetuated in local street names (Goodwin 1764, 157), and memories of the castle have persisted to be captured locally in art and architecture, not least in the design and decoration of the 19th- and 20th-century buildings constructed on and around its buried remains. The deer park has also had a significant impact on the development of Sheffield, as it remained open land until the 18th century, after which industrial activities began to impinge on it, although many parts of the park were not built on for housing until the 20th century. In this chapter we show how the archaeology of the castle and its wider landscape can be used to stimulate and inform the regeneration of an area that is now one of the most deprived wards in Sheffield but was once at its social, political and cultural heart. From the 1920s a substantial working-class social housing complex was built on much of the former deer park, and this estate has experienced considerable deprivation since then, being blighted by unemployment since the 1980s, with high levels of crime leading to the estate being dubbed in more recent times 'the worst in Britain' (McCaffrey 2007; Jackson 2016; Lee 2016). However, the sites of both the castle and its deer park and hunting lodge are now being used to inform regeneration (EDAW 2005) and the creation of new employment and social opportunities (Green Estate 2016), and these initiatives are detailed in this chapter, which also makes the case for the importance of researching and publishing the hidden heritage of urban communities, and the social and economic value of this into the 21 st century. This chapter also discusses recent work by University of Sheffield researchers from a diversity of disciplines to develop models for regeneration of the site of Sheffield Castle, in partnership with community group the Friends of Sheffield Castle (see Chapter 9), which are feeding into the City Council plans for the future. In an epilogue we show how we have succeeded in contributing a new dimension to the civic pride of Sheffield, and a new visual identity for ongoing regeneration debates through use of computer technology. This really matters in a city where a survey commissioned by the Council in 2013 from audience engagement consultancy Wafer Hadley revealed that $46 \%$ of the public were unaware that it had ever had a castle despite there being 60,000 visitors a week to the market hall on the site, the eponymous 
Castle Market! Such lack of public awareness has had profound consequences for the vitality and vibrancy of the city, as well as the identity and sense of place of its citizens. In this book, we respond to the challenges posed by an understudied and misunderstood urban archaeological site and show how the castle, as well as subsequent developments on the site, can be recovered from the archives and reimagined in placemaking in the 21 st century.

\section{Bibliography}

The full bibliography is available at the end of this volume, or at: https://doi.org/10.22599/SheffieldCastle.k. 